\title{
Análise de cenários resultantes da impermeabilização de espaços destinados à circulação e permanência de pedestres
}

Analysis of scenarios resulting from the soil sealing of spaces intended for the circulation and permanence of pedestrians

Geovana Geloni Parra[a] $@$, Bernardo Arantes do Nascimento Teixeira[b]

\begin{abstract}
[a] Universidade Federal de São Carlos (UFSCar), Programa de Pós-graduação em Engenharia Urbana, São Carlos, SP, Brasil
[b] Universidade Federal de São Carlos (UFSCar), Departamento de Engenharia Civil, Programa de Pós-graduação em Engenharia Urbana, São Carlos, SP, Brasil
\end{abstract}

Como citar: Parra, G. G., \& Teixeira, B. A. N. (2020). Análise de cenários resultantes da impermeabilização de espaços destinados à circulação e permanência de pedestres. urbe. Revista Brasileira de Gestão Urbana, 12, e20190265. https://doi.org/10.1590/2175-3369.012.e20190265

\section{Resumo}

A alta impermeabilização do solo decorrente do crescimento das cidades vem causando graves problemas urbanos, como o aumento das enchentes. Estas consequências impulsionaram o desenvolvimento de técnicas mais sustentáveis de drenagem urbana que auxiliam na mitigação destes eventos. Cerca de $20 \%$ da área impermeabilizada de uma cidade é destinada às vias de circulação de pedestres e veículos, o que confere a estas áreas grande importância para a ocorrência dos eventos de enchentes. A quantificação do escoamento superficial causado pelos Espaços de Circulação e Permanência de Pedestres (ECPP) em três espaços urbanos e a criação de cenários de possibilidades, alternativas de materiais e de projeto são os objetivos deste trabalho. Foram caracterizados três espaços diferentes, dentro de um campus universitário, em um calçadão e em um bairro, determinados os tipos de calçamentos, manutenção e sua contribuição para o escoamento superficial. Os resultados encontrados permitem concluir que a utilização de um desenho urbano com mais qualidade, mesclando áreas pavimentadas com grandes áreas verdes, pode ser uma alternativa mais econômica para a redução da impermeabilização do solo ou, quando impossível de ser adaptado, sejam utilizados os pisos drenantes que possuem níveis de infiltração muito próximos aos do solo gramado.

Palavras-chave: Pavimentos permeáveis. Escoamento superficial. Espaços de circulação. Permanência de pedestres.

\section{Abstract}

The high soil sealing due to the growth of cities has been causing serious urban problems, such as increased flooding. These consequences drove the development of more sustainable urban drainage techniques that help to mitigate these events. Average 20\% of the sealing area of a city is used for pedestrian and vehicle circulation routes, which gives these areas great importance for the occurrence of flood events. The runoff quantifying caused by the pedestrian circulation and permanence spaces (PCPS), in three urban spaces and the creation of scenarios of possibilities and alternatives for materials and design were the goals of

GGP é arquiteta e urbanista, mestre em Engenharia Urbana, doutoranda em Engenharia Urbana, e-mail: geovanaparra.arquiteta@gmail.com BANT é engenheiro civil, doutor em Engenharia Civil Hidráulica e Saneamento, e-mail: bernardo@ufscar.br 
this work. Three different spaces were characterized, one within a university campus, a boardwalk and a neighborhood. The types of pavements, maintenance and their contribution to runoff was determined. The results found allowed to conclude that the use of a better quality urban design, mixing paved areas, with large green areas can be a more economical alternative to reduce soil sealing, or when it is impossible to be adapted, draining floors are used which have infiltration levels very close to grassy soil.

Keywords: Permeable pavements. Runoff. Permanence spaces. Pedestrian circulation.

\section{Introdução}

As altas taxas de crescimento urbano nas cidades, juntamente com políticas urbanas ineficientes para o controle da impermeabilização do solo, têm provocado inúmeros problemas de inundações e danos na infraestrutura. Esses danos estão relacionados à pavimentação de vias (desgaste de asfalto, desalinhamento dos pavimentos intertravados), sobrecargas de poluentes nas estações de tratamento de água e esgoto, edificações localizadas em áreas de risco, prejuízos econômicos para cidadãos e para o poder público, além da possibilidade de proliferação de doenças de veiculação hídrica.

A pavimentação do solo tem uma grande contribuição no escoamento superficial de águas pluviais. É possível observar nas cidades que grande parte desta área pavimentada está destinada à circulação de pessoas e de veículos: são as calçadas e vias, e, segundo a Lei Federal 6766 de 19 de dezembro de 1999, as áreas destinadas à circulação são proporcionais à densidade de ocupação prevista pelo plano diretor ou aprovada por lei municipal (Brasil, 1979).

Muitos trabalhos vêm contabilizando as áreas impermeáveis destinadas aos veículos, porém pouco ainda se estuda a respeito da impermeabilização das áreas destinadas aos pedestres. Portanto é imprescindível um trabalho que estude e quantifique os efeitos dos Espaços de Circulação e Permanência de Pedestres (ECPP) na impermeabilização do espaço urbano sobre o manejo das águas pluviais.

Existe a necessidade de um estudo sobre formas alternativas de pavimentação que auxiliem em uma opção urbanística e paisagística para implantação de pavimentos que possibilitem o controle da drenagem urbana e o conforto do pedestre. Portanto, o objetivo deste trabalho é o estudo dos efeitos dos ECPPs sobre o manejo das águas de chuva, de forma a avaliar as condições físicas, aplicar cálculos hidrológicos, e considerações sobre os ECPPs de estudo, tendo como objeto empírico uma bacia experimental localizada no Campus da UFSCar em São Carlos/SP e também em duas áreas localizadas na cidade de São José do Rio Preto/SP.

Para a obtenção dos resultados, foram solicitados mapas e projetos dos ECPPs de estudo, visitas no EDF-Escritório de Desenvolvimento Físico da UFSCar, pesquisa em arquivos do Grupo de pesquisa G-Hidro e na Prefeitura Municipal de São José do Rio Preto. Foi realizado levantamento fotográfico das áreas de estudo, para caracterização das tipologias de pisos, sua manutenção e caracterização dos aspectos construtivos.

0 tratamento dos mapas e projetos dos ECPPs foi através dos softwares AUTOCAD, COREL DRAW e GOOGLE EARTH. Os cálculos de escoamento superficial e seus gráficos de representação foram trabalhados no software EXCEL.

A escolha do objeto de estudo da UFSCar se deve à possibilidade de integração entre as técnicas compensatórias implantadas, pesquisas finalizadas e em andamento no local. A escolha da cidade de São José do Rio Preto se justifica pela grande ocorrência de enchentes, inundações e seu alto crescimento urbano. Os objetos de estudo da cidade são o calçadão para pedestres localizado na área central, com índice alto de impermeabilização do solo, e também um bairro residencial, com características de implantação mais sustentáveis em relação a outros bairros com urbanização antiga e convencional. Os objetos de estudo foram caracterizados a partir de parâmetros que envolvem aspectos técnicos construtivos, de manutenção e de desenho urbano.

Uma das medidas de controle de águas pluviais são os pavimentos permeáveis que são superfícies porosas ou perfuradas que permitem a infiltração de parte do escoamento superficial. Estes são indicados 
para pavimentação de locais com pequena movimentação de veículos, estacionamentos e passeios públicos destinados aos pedestres.

Pesquisas realizadas vêm encontrando resultados referentes à funcionalidade hidrológica da pavimentação, como coeficientes de escoamento entre diferentes tipos de pavimentos. Resultados encontrados por Araújo et al. (2000) mostram que, em simulação de chuva, nos pavimentos permeáveis, praticamente não ocorreu escoamento superficial, não apenas mantendo as condições de pré-ocupação do solo, mas também podendo reduzir a zero a taxa de escoamento.

Já a pesquisa realizada por Bruno et al. (2013) também avalia experimentalmente as seguintes estruturas: solo gramado, solo exposto, concreto convencional e blocos de concreto convencionais maciços e vazados (Tabela 1), com simulação de chuva. A área está localizada no campus da Universidade Federal do Mato Grosso e o tipo de solo é argiloso. Cada parcela experimental tem $0,70 \mathrm{~m}^{2}$ de área e foram isoladas por um quadro metálico. Avalia o escoamento de água da chuva em duas situações de intensidade de precipitação: $79 \mathrm{~mm} / \mathrm{h}$ e $121 \mathrm{~mm} / \mathrm{h}$, com três ensaios em cada uma das cinco superfícies.

Tabela 1 - Taxas de infiltração média (mm/h) encontradas por Bruno et al. (2013)

\begin{tabular}{cccccc}
\hline Tipo de superfície & Solo gramado & Solo exposto & $\begin{array}{c}\text { Bloco de } \\
\text { concreto } \\
\text { maciço }\end{array}$ & $\begin{array}{c}\text { Bloco de } \\
\text { concreto } \\
\text { vazado }\end{array}$ & $\begin{array}{c}\text { Concreto } \\
\text { convencional }\end{array}$ \\
\hline $\begin{array}{c}\text { Intensidade de Precipitação } \\
79 \mathrm{~mm} / \mathrm{h}\end{array}$ & Infiltração total & 29,15 & 48,2 & 78,07 & 3,11 \\
$\begin{array}{c}\text { Intensidade de Precipitação } \\
121 \mathrm{~mm} / \mathrm{h}\end{array}$ & 96,3 & 42,85 & 48,71 & 84 & 6,01 \\
\hline
\end{tabular}

Fonte: Adaptado de Bruno et al. (2013).

A superfície de grama foi a que apresentou melhor resultado, obtendo escoamento apenas na simulação de chuva de $121 \mathrm{~mm} / \mathrm{h}$, sendo o coeficiente de escoamento de 0,15 . Com este resultado, percebe-se a importância dos impactos causados pela retirada de vegetação do solo, em relação ao escoamento superficial gerado durante os eventos de chuva. Sendo assim, se faz necessária a busca de alternativas de revestimentos do solo que possam minimizar os impactos causados ao meio natural.

A avaliação de características e informações de fabricantes de pavimentos hidrologicamente funcionais e de artigos científicos foi estudada por Parra \& Teixeira (2015). No estudo, os resultados comprovaram que o concreto poroso apresenta índices muito próximos ao do solo gramado, e o solo exposto, índices comparados ao bloco de concreto convencional.

Os ECPPs devem ser integrados à paisagem urbana e atender aos quesitos necessários ao desenho universal. Quando o acesso de pessoas com deficiência ou mobilidade reduzida é garantido, qualquer pessoa pode ter acesso ao espaço. Neste contexto, a Norma Brasileira NBR 9050 auxilia o desenho urbano e arquitetônico em parâmetros de dimensionamento para os ECPPs.

Segundo a norma NBR 9050, as calçadas podem ser divididas em três faixas: a primeira, de serviços (largura de $0,75 \mathrm{~m}$ ); a segunda, livre para circulação (largura mínima 1,20m); e a terceira, de acesso ao lote (largura variável dependendo da dimensão da calçada) (ABNT, 2015). A mesma norma ainda define que a inclinação transversal da calçada não pode ser superior a $3 \%$, e longitudinalmente deve acompanhar a inclinação da via.

A cidade de São Paulo (2011) por meio da Lei Municipal no 15.442 de 2012 estabelece uma forma de fiscalização e padronização de construção dos ECPPs. A partir de uma cartilha explicativa, orienta a população sobre a forma de execução de sua calçada, utilizando os mesmos princípios da norma NBR 9050, além disso, ainda determina quais os tipos de pavimentação podem ser executados nas calçadas (Tabela 2). 
Tabela 2 - Tipos de pavimentos sugeridos pela Cartilha Passeio Livre

\begin{tabular}{|c|c|}
\hline $\begin{array}{l}\text { Tipo de via pelo Plano Diretor } \\
\text { Regional }\end{array}$ & Material Adequado \\
\hline $\begin{array}{c}\text { Tipo de via pelo Plano Diretor } \\
\text { Regional }\end{array}$ & $\begin{array}{c}\text { Placas pré-moldadas de concreto, concreto armado, moldado no local, ladrilho } \\
\text { hidráulico e piso intertravado }\end{array}$ \\
\hline Via Local & $\begin{array}{c}\text { Placas pré-moldadas de concreto, concreto armado, moldado no local, ladrilho } \\
\text { hidráulico e piso intertravado }\end{array}$ \\
\hline Via Coletora & Concreto armado, moldado no local e ladrilho hidráulico \\
\hline Via Coletora com comércio & Concreto armado, moldado no local e ladrilho hidráulico \\
\hline Via Estrutural & Concreto armado, moldado no local e ladrilho hidráulico \\
\hline Via Estrutural com comércio & Concreto armado, moldado no local e ladrilho hidráulico \\
\hline
\end{tabular}

Fonte: Adaptado de Prefeitura de São Paulo (2012).

Wang et al. (2010) encontraram resultados que avaliam a aplicação de pavimentos permeáveis em calçadas quanto aos benefícios térmicos e de redução do escoamento de água de chuva. A temperatura da superfície de aplicação começou a cair após a ocorrência de chuva, de tal modo que a sua capacidade de refrigeração e duração do resfriamento final depende principalmente da temperatura ambiente e da capacidade de retenção de água do pavimento permeável.

Os Sistemas de Drenagem Urbana Sustentáveis (SUDS) são utilizados por Ferguson (2012) para reproduzir um modelo unificado de desenho urbano. Ele utiliza pavimentos permeáveis de dois tipos: o concreto poroso, feito com agregados de tamanhos únicos, que criam uma rede de espaços vazios, adequada ao tráfego leve e médio, e permeável o suficiente para suportar qualquer nível de chuva natural. Além desse, outro tipo são os blocos de pavimentação articulados abertos, são blocos de concretos ou cerâmicos, moldados com espaços abertos nas articulações, que são cheias de agregados altamente permeáveis. Dessa maneira o autor também integra o espaço com outras técnicas vantajosas à drenagem urbana como a implantação dos jardins de chuva ou de biorretenção, aptos a receber o excesso de água das superfícies adjacentes, filtrando, tratando e auxiliando na evapotranspiração da vegetação.

A partir dos estudos apresentados e com as normas técnicas que devem ser seguidas, são observadas as possibilidades de integração da acessibilidade e execução dos ECPPs. A utilização de pisos drenantes ou permeáveis se mostraram muito eficientes, chegando ao escoamento superficial quase $0 \%$ ou próximo da casa dos $80 \%$ de infiltração. Outra possibilidade seria a implantação de áreas verdes de infiltração próximas aos ECPPs, que contribuem não só para a alta taxa de infiltração de água de chuva como também para a redução da temperatura do ambiente. 0 planejamento integrado dos sistemas urbanos deve contemplar a utilização dos pavimentos hidrologicamente funcionais como meio de reduzir os impactos causados pelo escoamento superficial das águas de chuva. Ajudando a reduzir a impermeabilidade do solo, diminuindo enchentes, facilitando o enraizamento, crescimento de plantas e árvores, como também as trocas de ar e água, e permite a manutenção de uma temperatura agradável no ambiente.

\section{Desenvolvimento}

Os estudos de casos escolhidos são áreas bem distintas entre si, essa escolha aconteceu de forma a mostrar que existem especificidades dos estudos que são comuns, e outras que esclarecem como o desenho urbano pode ser implantado de maneira diferente em cada um deles.

O ECPP UFSCar é uma área de urbanização diferenciada em relação a uma cidade, existem grandes áreas calçadas para circulação de pedestres e também grandes áreas verdes. Suas legislações não obedecem a critérios de parcelamento urbano referentes às legislações municipais, seu ordenamento acontece de acordo com um Plano de desenvolvimento físico-territorial elaborado pelo Escritório de Desenvolvimento Físico da Universidade.

O ECPP Bairro possui urbanização de acordo com a Lei Federal de Parcelamento do Solo (Lei 6766) e também com as leis municipais. Sua escolha se deve por estar enquadrado em legislações mais sustentáveis relacionadas ao desenho urbano e à drenagem de águas pluviais. 
Em relação ao ECPP Calçadão, que mesmo estando dentro de uma área urbana e central em uma cidade de porte médio, não atende às legislações de Parcelamento do Solo e Lei de Zoneamento em vigor no município. Por se tratar de uma região antiga e de tratamento especial no Plano Diretor, não atende a porcentagens de permeabilidade e ocupação do solo.

Caracterização da área de estudo 1: campus UFSCar - São Carlos/SP

0 local de estudo pertence a uma das sub-bacias hidrográficas do córrego Monjolinho, dentro da área do Campus da Universidade Federal de São Carlos (Figura 1). A escolha da microbacia experimental da UFSCar foi determinante devido aos estudos e pesquisas relacionados à drenagem urbana já existentes no local e à possibilidade de integração com as técnicas compensatórias implantadas. 0 local também é rico em ECPPs e com grande número de usuários.

A dimensão total da área escolhida é de $49.075,69 \mathrm{~m}^{2}$, sendo exclusiva de calçadas a de $5.379,43 \mathrm{~m}^{2}$, o que representa em torno de $11 \%$ do total, sendo que o restante se distribui entre edificações, estacionamentos e áreas gramadas (Tabela 3).

Tabela 3 - Quadro de Áreas da microbacia experimental - UFSCar

\begin{tabular}{ccc}
\hline & $\mathbf{m}^{2}$ & $\%$ \\
\hline MICROBACIA & $49.075,69$ & $100 \%$ \\
ECPP & $5.379,43$ & $10,96 \%$ \\
EDIFICAÇÕES CONSTRUÍDAS & $5.101,02$ & $10,39 \%$ \\
ESTACIONAMENTOS & $5.276,54$ & $10,75 \%$ \\
GRAMA & $33.318,70$ & $67,89 \%$ \\
\hline
\end{tabular}

Fonte: Autores (2015).

A Tabela 3 mostra que a porcentagem de áreas destinadas aos ECPPs é quase a mesma das projeções de áreas construídas das edificações, bem como a da área destinada ao estacionamento de veículos.

A UFSCar não apresenta área de inundações ou enchentes em seu território, mas sua bacia contribui para a bacia hidrográfica do rio Monjolinho que todos os anos sofre enchentes com as chuvas de verão.

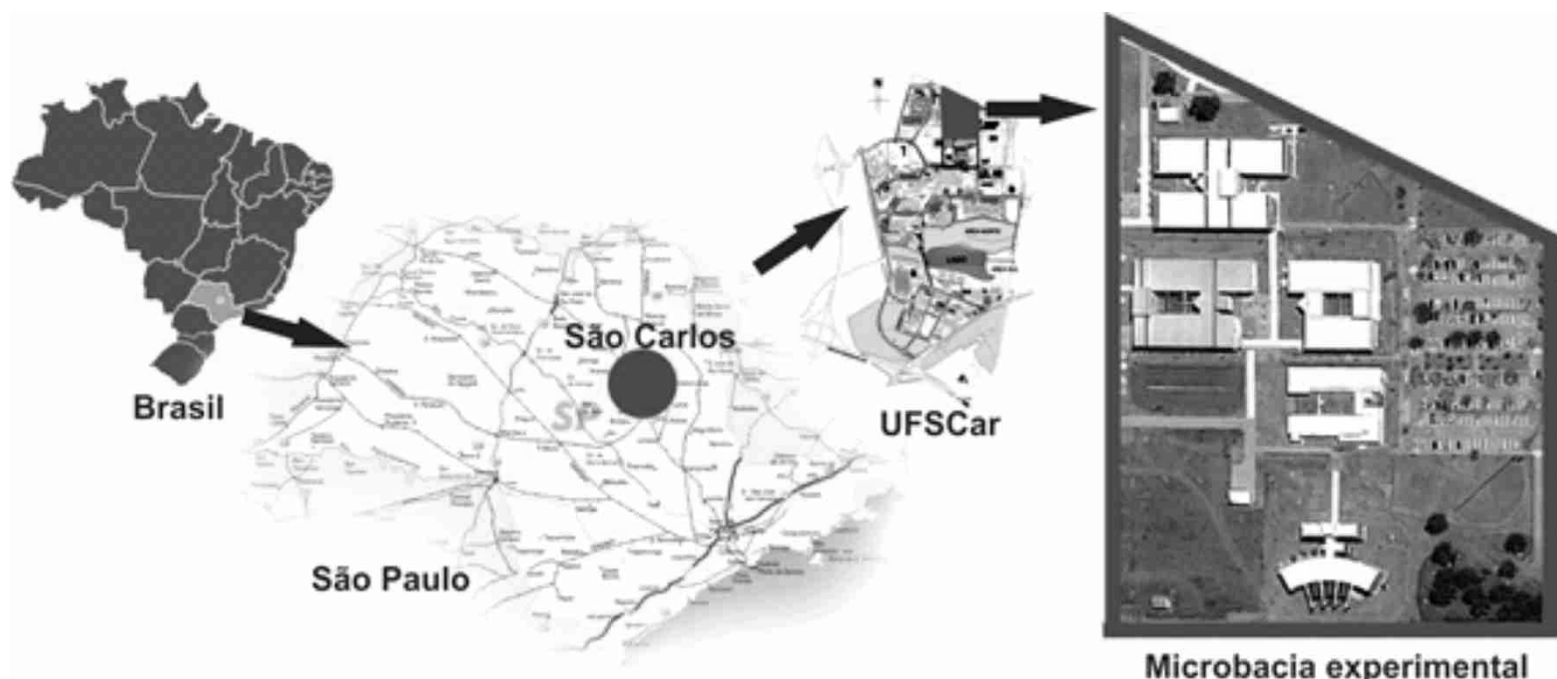

Figura 1 - Localização do objeto de estudo. Fonte: Autores (2015).

O diagnóstico físico do espaço consistiu no levantamento fotográfico dos ECPPs dentro da bacia experimental (Figura 2). Foram verificados os tipos de pisos executados em cada espaço, a manutenção destes pisos e como acontece a utilização pelos pedestres (Tabela 4). 
Os levantamentos fotográficos foram realizados durante o período de março de 2014 a setembro de 2015. No primeiro levantamento, em 18/03/2014, observaram-se os tipos de pisos e suas características, seus comportamentos em períodos pós-chuva e durante chuva, e sua manutenção ao longo do tempo. Na Figura 2, foram determinados os pontos observados durante os levantamentos, estes estão simbolizados por letras (A a J), totalizando 10 pontos de observação.

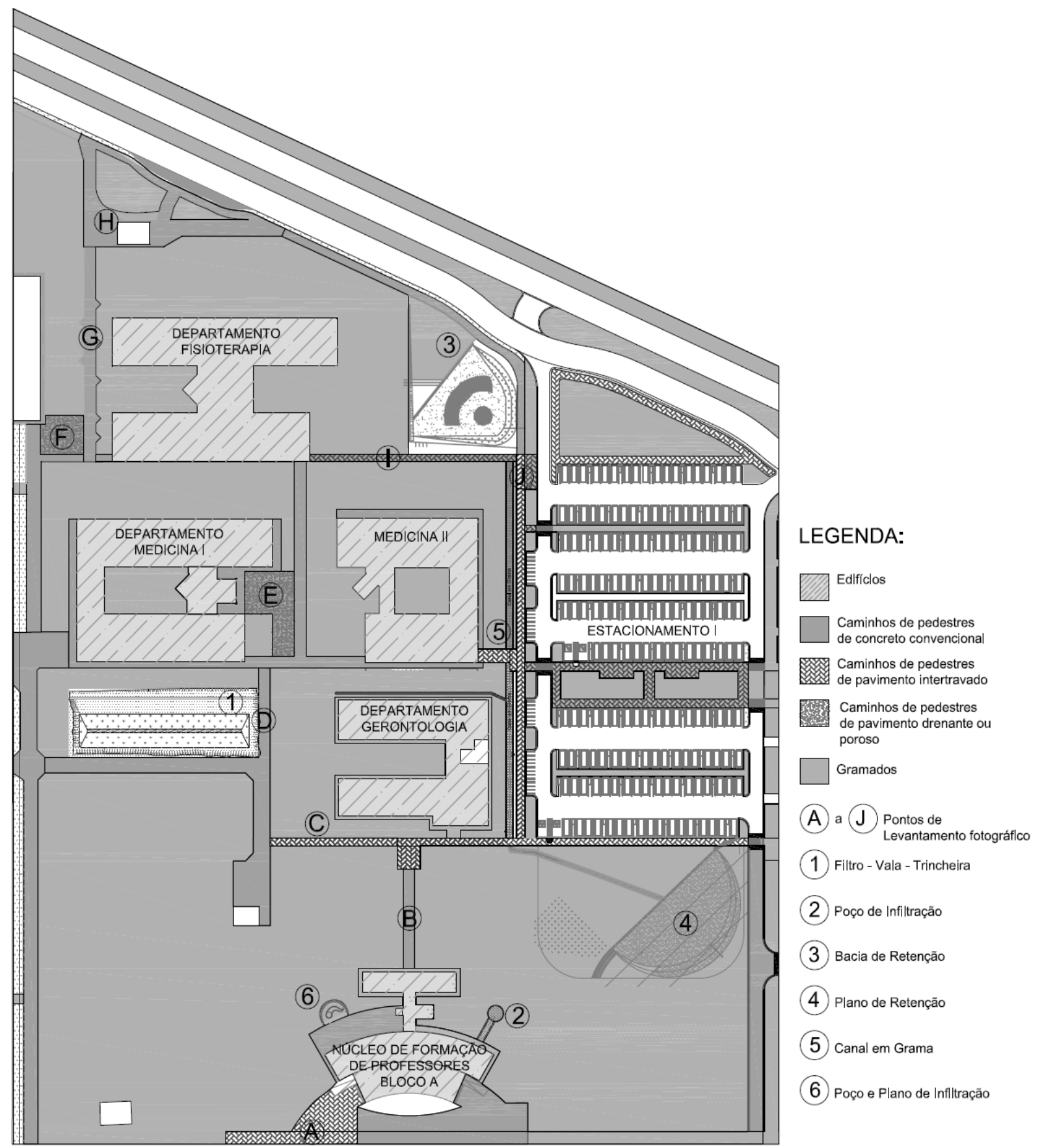

Figura 2 - Mapeamento dos tipos de pavimentos na bacia experimental localizada no campus da UFSCar. Fonte: Autores (2015). 
Tabela 4 - Síntese da descrição dos ECPPs UFSCar

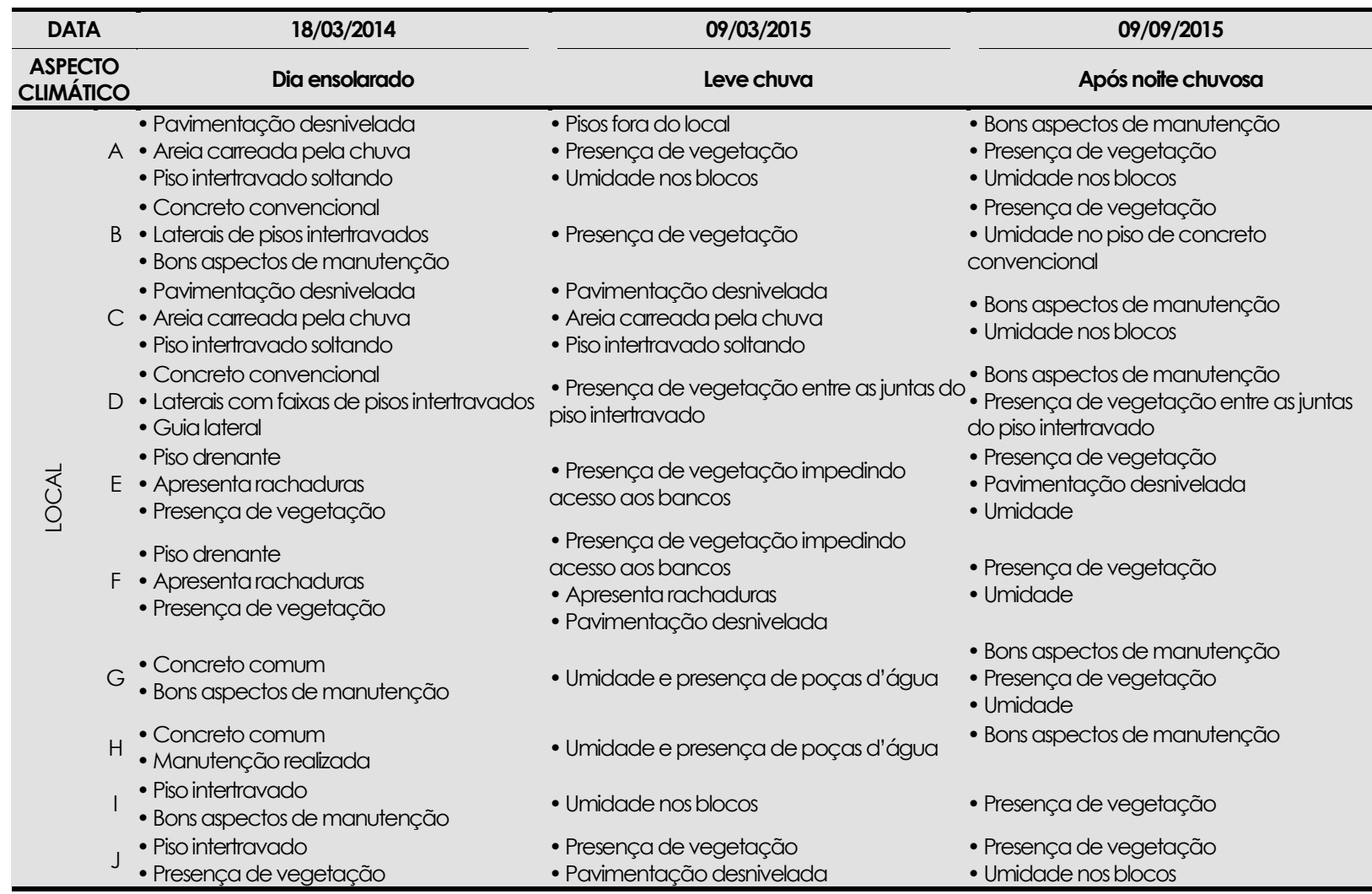

Fonte: Autores (2015).

\section{Caracterização da área de estudo 2: ECPP calçadão de São José do Rio Preto}

São José do Rio Preto está localizada no noroeste do Estado de São Paulo (Figura 3), segundo o Censo 2010, possui 408.258 habitantes e uma área 431,96km². A pesquisa do IBGE (2010) estima que em 2014 a população tenha alcançado 438.354 habitantes.

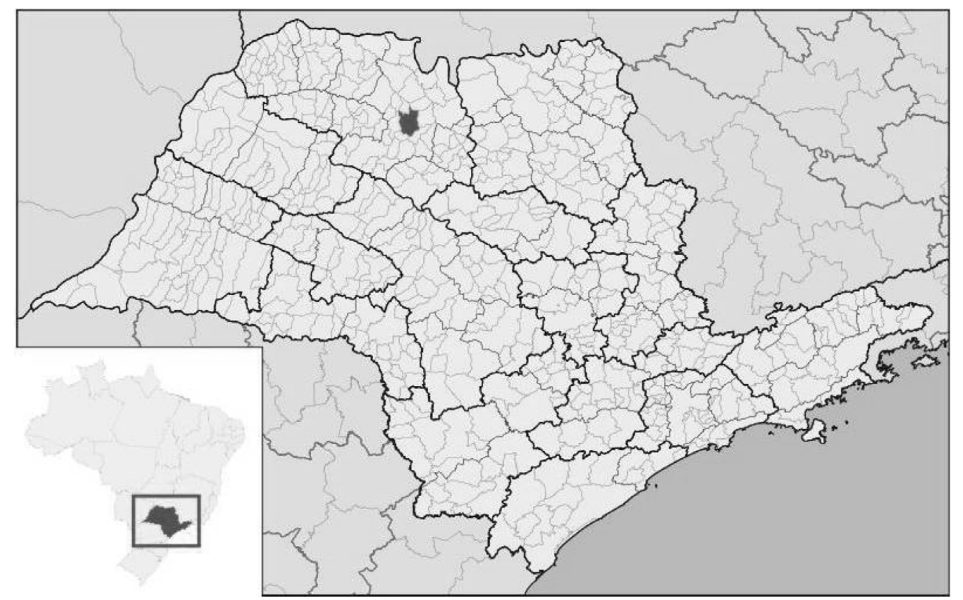

Figura 3 - Localização de São José do Rio Preto em relação ao Estado de São Paulo e ao Brasil. Fonte: Rio Preto Classificados (2015).

A alta impermeabilização do solo decorrente do processo de urbanização de São José do Rio Preto contribui de maneira significativa para a ocorrência de enchentes e inundações nas principais avenidas da cidade, construídas sobre rios que foram canalizados no passado. 0 ECPP escolhido para este estudo, popularmente conhecido como 
Calçadão, apresenta uma área total de $67.646 \mathrm{~m}^{2}$, considerando somente as áreas destinadas aos ECPPs e pequenos espaços gramados, o total é de $30.738 \mathrm{~m}^{2}$; a área destinada às quadras com edificações é de $36.908 \mathrm{~m}^{2}$.

O local pode ser um grande contribuinte para os eventos de enchentes na Avenida Bady Bassit e na região da Rodoviária Municipal, pois está localizado em uma área alta entre duas principais avenidas da cidade que cobrem dois importantes córregos do município que foram canalizados. Parra et al. (2011) mapearam próximo ao ECPP cerca de 5 pontos de inundação. Após a realização de um levantamento fotográfico no local (Figura 4), e análise dos projetos encontrados na Prefeitura Municipal, foi possível realizar a elaboração da Tabela 5.

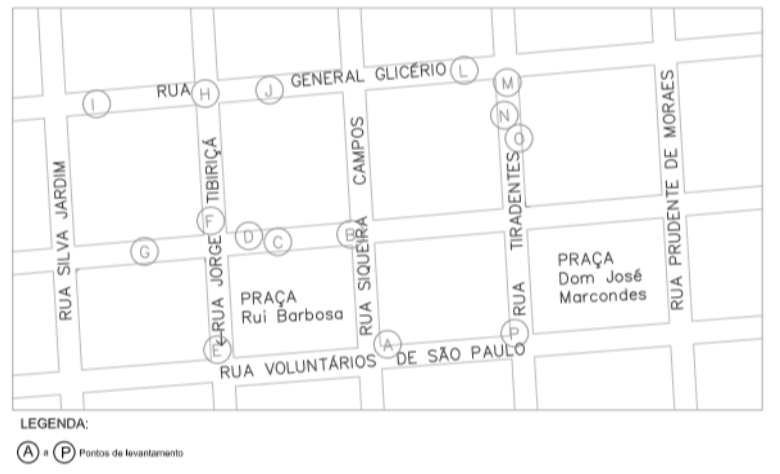

Figura 4 - Planta do Calçadão de São José do Rio Preto com a localização dos pontos levantados. Fonte: Autores (2016).

Tabela 5 - Síntese de descrição do ECPP Calçadão

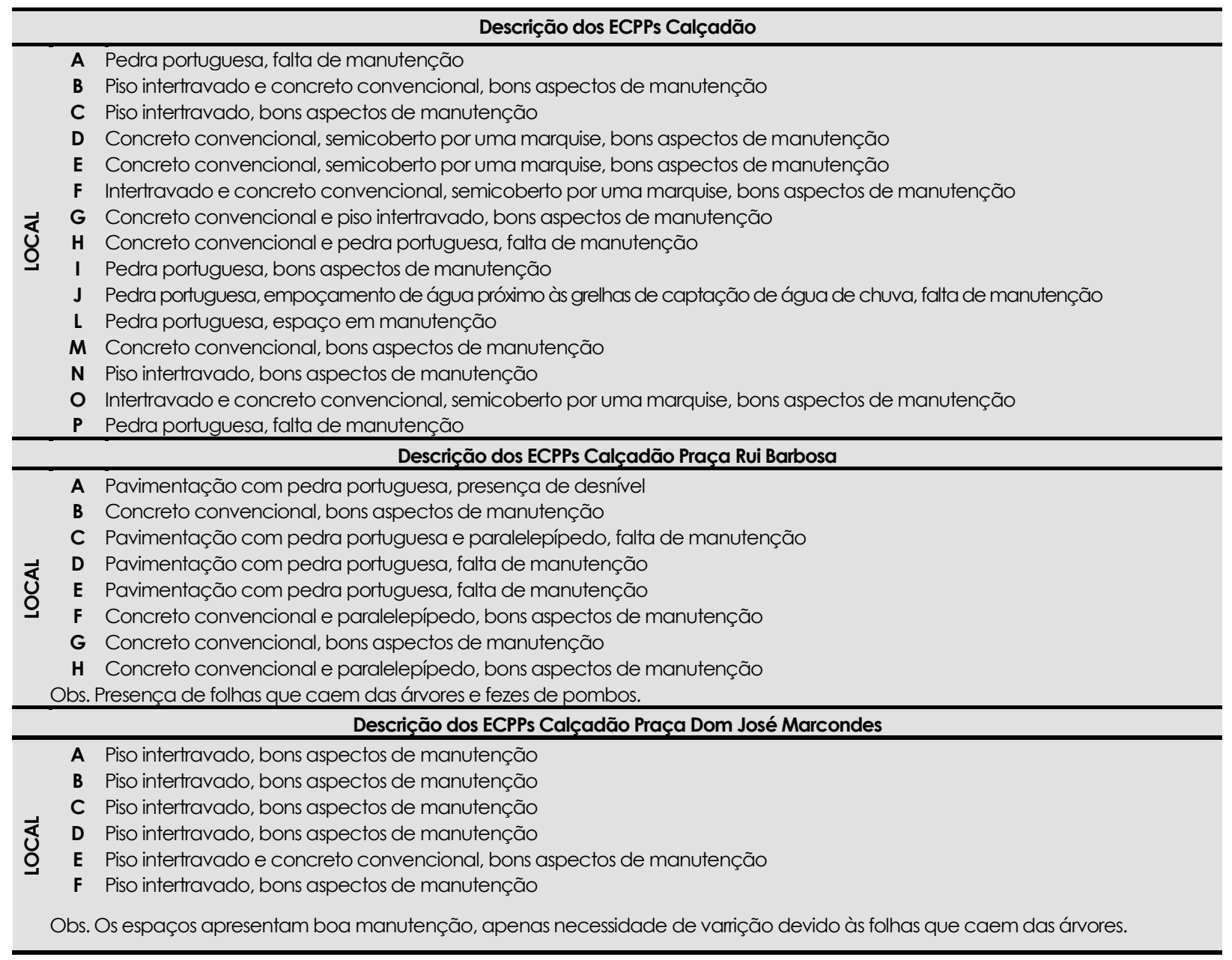

Fonte: Autores (2015). 


\section{Caracterização da área de estudo 3: ECPP bairro de São José do Rio Preto}

O ECPP escolhido como área de estudo 3 é o bairro Jardim Indianápolis, localizado em São José do Rio Preto. A escolha de um bairro como terceiro objeto de estudo, que deve seguir a legislação de parcelamento, uso e ocupação do solo municipal, se justifica com o objetivo de comparar os resultados encontrados no ECPP UFSCar, queé uma área atípica onde não se aplica uma legislação municipal relativa ao tema, com os resultados encontrados no ECPP Calçadão, área altamente impermeabilizada e somente destinada ao deslocamento de pedestres.

Os três estudos são diferentes entre si do ponto de vista da ocupação e uso do solo, porém os 3 mostram grandes porcentagens de áreas destinadas aos pedestres e, dessa forma, possibilitam avaliar a melhor solução para estes espaços do ponto de vista da drenagem.

A escolha deste bairro aconteceu a partir da seleção de loteamentos abertos implantados após a Legislação Municipal 10.822/2010 de 17 de novembro de 2010 que dispõe sobre o Programa de Recuperação e Preservação da Permeabilidade do Solo, além do embelezamento do espaço no município de São José do Rio Preto, com a implantação das "Calçadas Verdes", e a Lei Municipal 10.290 de 24 de dezembro de 2008 que cria no município o Programa de Gestão das Águas Superficiais da Bacia Hidrográfica do Rio Preto e dá outras providências. Esta lei determina que todas as edificações a serem construídas com área maior que $100 \mathrm{~m}^{2}$ devem possuir dispositivo de retenção ou detenção de águas pluviais, e todo novo empreendimento que importe em parcelamento do solo urbano ou incorporação imobiliária deverá prever na sua implantação o limite de vazão máxima específica. Sendo que toda edificação a ser construída em um novo empreendimento que atenda a esta lei está desobrigada de construir o dispositivo individual de retenção ou detenção de águas pluviais (São José do Rio Preto, 2010).

O alvará de construção do loteamento é datado do ano de 2008, e, portanto, atende à legislação 10.290/2008. A autorização para a construção de edificações ocorreu em 2010, portanto grande parte das construções existentes no local são obrigadas a atender à Lei 10.822/2010.

0 projeto do loteamento previu a coleta das águas pluviais em sistema de drenagem convencional, direcionando para a bacia de detenção localizada no ponto mais baixo da área. Na Figura 5, está implantada a bacia de detenção de águas pluviais e a divisão dos lotes. Foi realizado um levantamento fotográfico no local para verificar as condições dos ECPPs existentes, os tipos de pisos e quais deles atendiam à Lei 10.822/2010. A partir destes dados, a Tabela 6 foi produzida. Nela estão descritos os aspectos construtivos e de manutenção dos ECPPs.

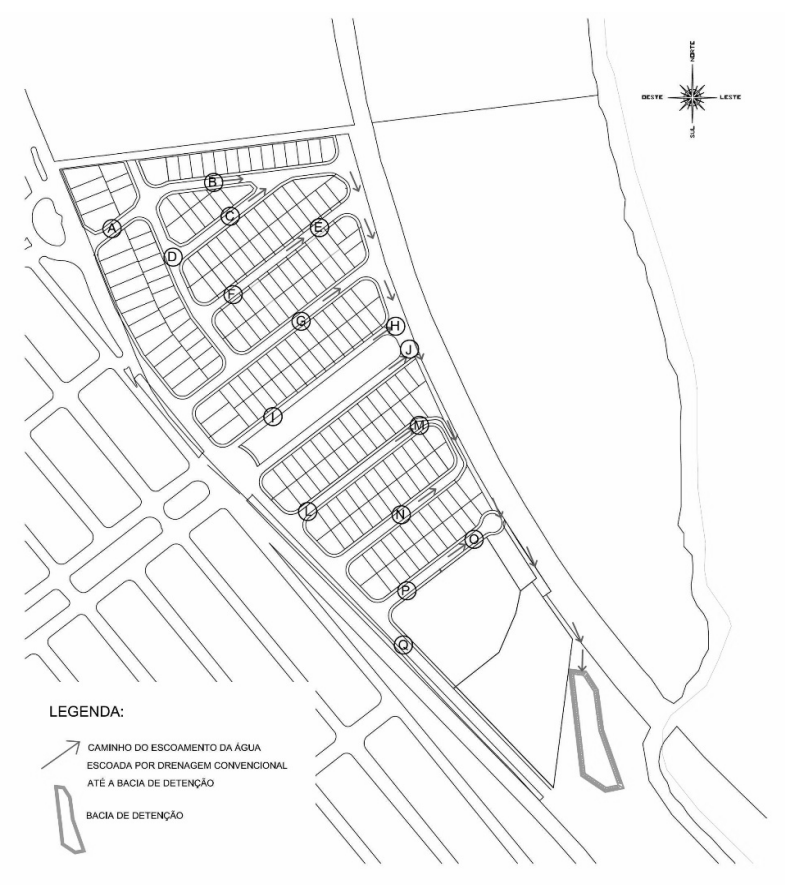

Figura 5 - Indicação dos pontos do levantamento e do escoamento das águas de chuva do ECPP bairro aprovado na Prefeitura Municipal. Fonte: Adaptado de Prefeitura Municipal de São José do Rio Preto (2015). 
Tabela 6 - Síntese descrição do ECPP Bairro

\begin{tabular}{|c|c|c|}
\hline \multicolumn{3}{|r|}{ Descrição do ECPP Bairro } \\
\hline LOCAL & $\begin{array}{l}J \\
L \\
M \\
N \\
O \\
P \\
Q\end{array}$ & $\begin{array}{l}\text { - Calçamento de concreto convencional com faixa gramada } \\
\text { - Bons aspectos de manutenção } \\
\text { - Utilização como estacionamento } \\
\text { - Calçamento de concreto convencional } \\
\text { - Calçamento de concreto convencional } \\
\text { - Manutenção inadequada } \\
\text { - Crescimento de vegetação entre rachaduras do pavimento } \\
\text { - Bloqueio do passeio por meio de materiais de construção } \\
\text { - Calçamento de concreto convencional com faixa gramada } \\
\text { - Espaço bem arborizado } \\
\text { - Bons aspectos de manutenção } \\
\text { - Calçamento de concreto convencional e de cerâmica com e sem faixa gramada } \\
\text { - Calçamento de concreto convencional com faixa gramada } \\
\text { - Calçamento de concreto convencional e cerâmica } \\
\text { - Espaço sem calçamento para pedestres } \\
\text { - Lixo acumulado na sarjeta } \\
\text { - Vegetação alta } \\
\text { - Calçamento convencional } \\
\text { - Canteiro central da via sem calçada para pedestres } \\
\text { - Bons aspectos de manutenção } \\
\text { - Espaço não edificado com vegetação alta, cercado e sem pavimentação } \\
\text { - Pisos desnivelados } \\
\text { - Calçamento de concreto convencional com faixa gramada } \\
\text { - Calçamento de concreto convencional e de cerâmica com e sem faixa gramada } \\
\text { - Calçamento em cerâmica } \\
\text { - Jardim ao invés de faixa gramada } \\
\text { - Calçamento de concreto convencional com faixa gramada } \\
\text { - de concreto convencional e de cerâmica com e sem faixa gramada }\end{array}$ \\
\hline
\end{tabular}

Fonte: Autores (2015).

\section{Resultados e discussões}

\section{Resultados encontrados no ECPP 1: campus UFSCar - São Carlos/SP}

Foi considerado que nem todos os ECPPs estão diretamente conectados à rede de drenagem de águas pluviais. Assim, foram separados 10 exutórios para a microbacia, locais em que a água de chuva escoa para os gramados e locais onde escoa para as técnicas compensatórias ou para a rede de drenagem. Conforme o mapa da Figura 6. 


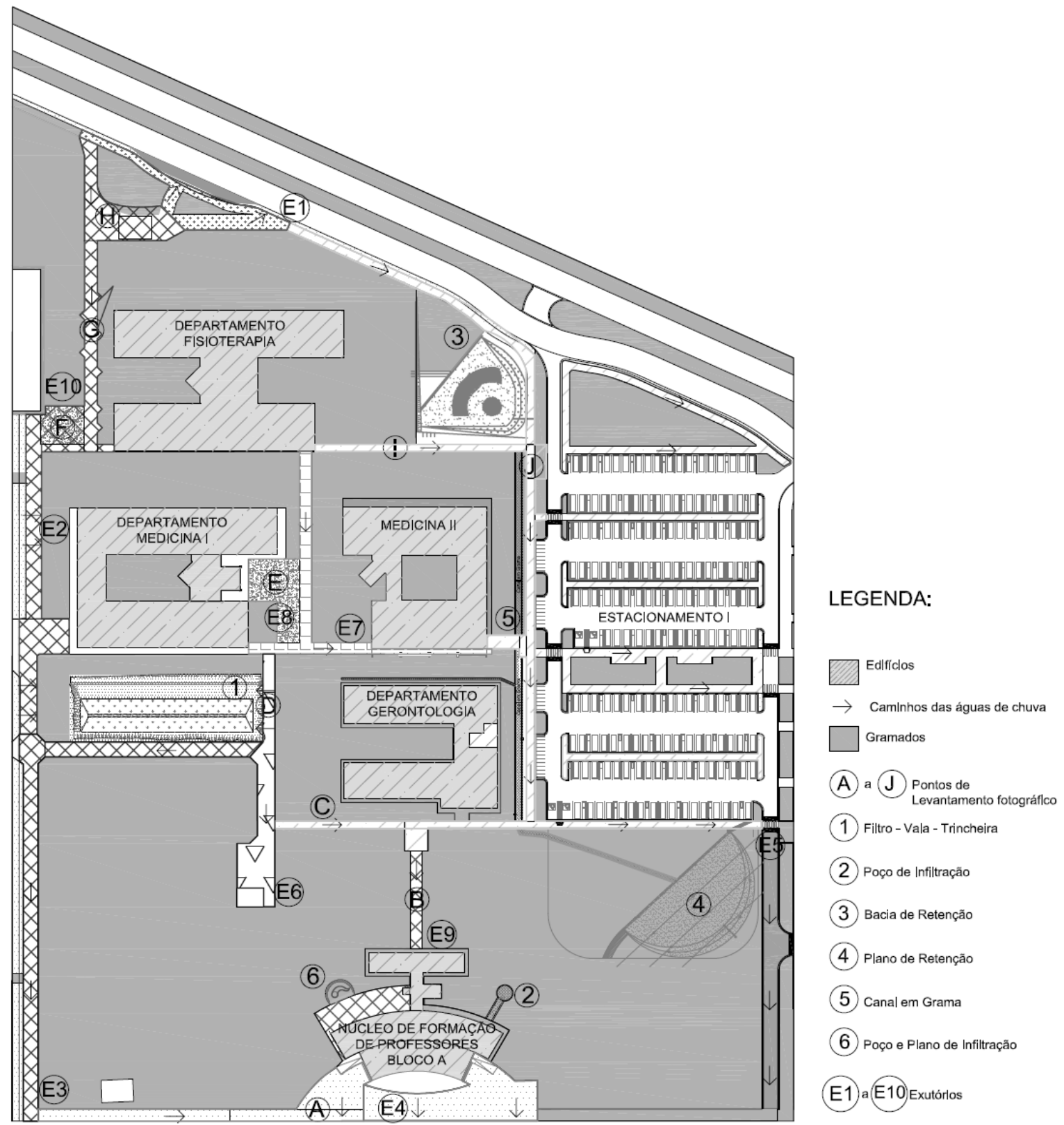

Figura 6 - Delimitação dos exutórios do ECPP-UFSCar. Fonte: Autores (2015).

Com os dados obtidos nos levantamentos fotográficos e a partir da definição dos exutórios, a Tabela 7 comparativa entre o cenário real (situação existente) favorável e desfavorável foi elaborada com as áreas de contribuição e suas porcentagens de cada cenário apresentado. 0 cenário favorável considera que todos os ECPPs estariam desconectados da rede de drenagem convencional e direcionados para o gramado, sendo este o melhor em condições de infiltração de águas pluviais sem a necessidade de infraestrutura adicional de drenagem, o cenário desfavorável considera que todos estão diretamente conectados na rede convencional de drenagem, sem possibilidade de infiltração da água de chuva no solo.

As áreas e porcentagens de contribuição para o escoamento superficial foram obtidas através da Fórmula 1:

$A a=C \times A$

sendo: $\mathrm{Aa}=$ Área efetiva de contribuição; $\mathrm{C}=$ Coeficiente de escoamento; $\mathrm{A}$ = Área total real. 
A fórmula se refere à metodologia simplificada de dimensionamento de técnicas compensatórias, em que é possível encontrar a área de contribuição para o escoamento superficial de uma microbacia. O coeficiente de escoamento foi substituído pelos valores referentes ao coeficiente do solo gramado, coberturas, concreto convencional, piso drenante e intertravado. Os valores de coeficiente de escoamento segundo Baptista et al. (2005) podem ser assimilados ao coeficiente de impermeabilização, ou seja, à relação entre as superfícies impermeáveis que contribuem para o escoamento total da bacia.

Tabela 7 - Síntese de características da Microbacia experimental

\begin{tabular}{|c|c|c|c|c|c|c|c|c|}
\hline \multirow[b]{2}{*}{$\begin{array}{l}\text { CARACTERÍSTICAS } \\
\text { DA MICROBACIA } \\
\text { EXPERIMENTAL }\end{array}$} & \multirow[b]{2}{*}{$\mathrm{m}^{2}$} & \multirow[b]{2}{*}{$\%$} & \multicolumn{2}{|c|}{ Cenário Real } & \multicolumn{2}{|c|}{ Cenário Favorável } & \multicolumn{2}{|c|}{ Cenário Desfavorável } \\
\hline & & & $\begin{array}{c}\text { Área de } \\
\text { Contribuição } \\
\text { para o } \\
\text { escoamento } \\
\text { superficial } \\
\left(m^{2}\right)\end{array}$ & $\begin{array}{c}\text { Escoamento } \\
\text { Superficial }\end{array}$ & $\begin{array}{l}\text { Área de } \\
\text { Contribuição } \\
\text { para o } \\
\text { escoamento } \\
\text { superficial } \\
\left(m^{2}\right)\end{array}$ & $\begin{array}{l}\text { Escoamento } \\
\text { Superficial }\end{array}$ & $\begin{array}{l}\text { Área de } \\
\text { Contribuição } \\
\text { para o } \\
\text { escoamento } \\
\text { superficial } \\
\left(m^{2}\right)\end{array}$ & $\begin{array}{l}\text { Escoamento } \\
\text { Superficial }\end{array}$ \\
\hline $\begin{array}{l}\text { ÁREA TOTAL DA } \\
\text { MICROBACIA } \\
\text { ÁREA }\end{array}$ & 49.268 & $100 \%$ & 11.999 & $24 \%$ & 10.346 & $21 \%$ & 21.894 & $44 \%$ \\
\hline $\begin{array}{l}\text { EDIFICAÇÕES } \\
\text { CONSTRUIIDAS }\end{array}$ & 5.101 & $10 \%$ & 1.071 & $2 \%$ & 1.071 & $2 \%$ & 4.591 & $9 \%$ \\
\hline DESCONECTADAS & & & & & & & & \\
\hline $\begin{array}{l}\text { ÁREA ECPP } \\
\text { TOTAL ÁREA }\end{array}$ & 5.572 & $11 \%$ & 2.822 & $6 \%$ & 1.169 & $2 \%$ & 5.293 & $11 \%$ \\
\hline $\begin{array}{l}\text { DESTINADA A } \\
\text { VEÍCULOS }\end{array}$ & 5.277 & $11 \%$ & 1.108 & $2 \%$ & 1.108 & $2 \%$ & 5.013 & $10 \%$ \\
\hline ÁREA GRAMADA & 33.319 & $68 \%$ & 6.997 & $14 \%$ & 6.997 & $14 \%$ & 6.997 & $14 \%$ \\
\hline
\end{tabular}

Fonte: Autores (2015).

Nesta Tabela 7, é observado que o cenário real em comparação à área de contribuição em $\mathrm{m}^{2}$ do escoamento superficial está 3\% acima do que seria o cenário favorável. Já o cenário desfavorável praticamente dobra a porcentagem de contribuição, somente a área dos ECPPs incrementa em sua contribuição cerca de $5 \%$.

Mas, para o estudo de caso da microbacia experimental do campus, o cenário favorável seria uma solução facilmente de ser implantada, devido à grande área gramada ao redor dos ECPPs, sem a necessidade de alteração dos tipos de pavimentações.

\section{Resultados encontrados no ECPP 2: calçadão - São José do Rio Preto/SP}

Para melhor entendimento do espaço e da sua contribuição para o escoamento superficial, o ECPP foi dividido em cinco microbacias, de acordo com os seus exutórios. A Figura 7 apresenta um esquema ilustrativo desta divisão mostrando o sentido do escoamento das águas. 

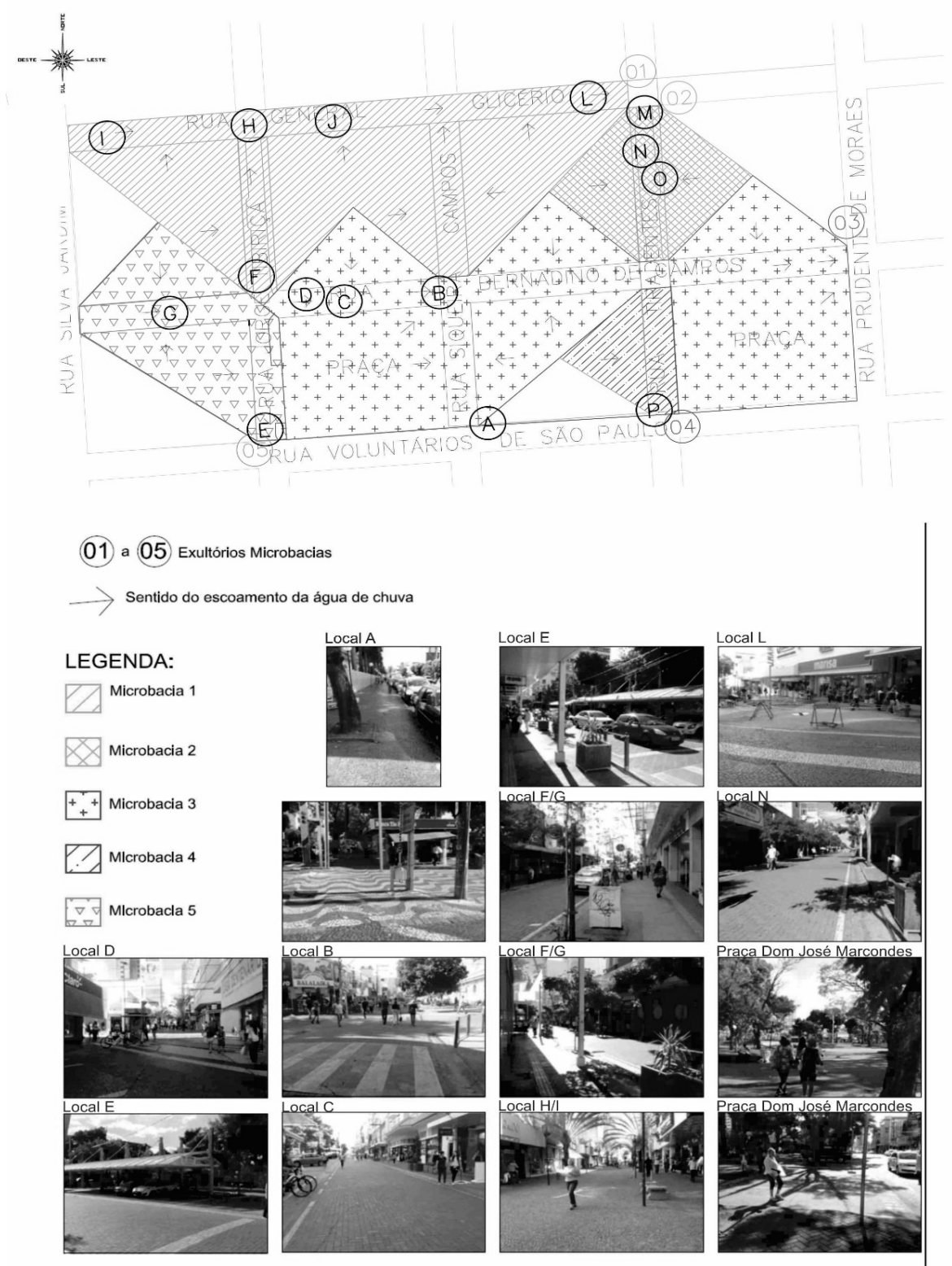

Figura 7 - Divisão por microbacias ECPP calçadão e levantamento fotográfico. Fonte: Autores (2015).

A partir desta divisão em microbacias, a mesma metodologia aplicada no ECPP UFSCar foi utilizada nos cálculos deste ECPP. Três cenários mostram em tabelas os resultados da situação real, a desfavorável e a favorável, que, no caso, ao invés de se utilizar gramados para o escoamento e infiltração de água de chuva, foi utilizado o piso drenante poroso, considerado entre todos os pavimentos o com maior potencial de infiltração.

A escolha da troca de pavimentação, ao invés da proposta de um novo desenho urbano para o calçadão, se justifica pela necessidade de se manter grandes espaços de circulação para os pedestres, com garantia de boa acessibilidade. 0 calçadão recebe mais de 200 mil pessoas por mês, e é um importante centro de compras para toda a região de São José do Rio Preto. Seria necessária uma reforma rápida a fim de não implicar comprometimento no funcionamento de lojas existentes no local. Um novo desenho urbano levaria muito tempo para ser implantado e reduziria a área útil para circulação de pedestres.

A Tabela 8, se refere à síntese dos cenários do ECPP Calçadão, nela estão inseridas as 5 microbacias e seus 3 cenários. A utilização do piso drenante em todo o ECPP possibilitaria que este contribuísse com apenas $0,2 \%$ do escoamento superficial, enquanto que no cenário real contribui em $35 \%$, apenas $11 \%$ abaixo da contribuição do Cenário Desfavorável. 
Tabela 8 - Síntese dos cenários do ECPP Calçadão

\begin{tabular}{|c|c|c|c|c|c|c|c|c|}
\hline \multirow[b]{2}{*}{$\begin{array}{l}\text { CARACTERÍSTICAS } \\
\text { ECPP CALÇADÃO }\end{array}$} & \multirow[b]{2}{*}{$\mathrm{m}^{2}$} & \multirow[b]{2}{*}{$\%$} & \multicolumn{2}{|c|}{ Cenário Real } & \multicolumn{2}{|c|}{ Cenário Favorável } & \multicolumn{2}{|c|}{ Cenário Desfavorável } \\
\hline & & & $\begin{array}{c}\text { Área de } \\
\text { Contribuição } \\
\text { para o } \\
\text { escoamento } \\
\text { superficial }\left(m^{2}\right)\end{array}$ & $\begin{array}{l}\text { Escoamento } \\
\text { Superficial }\end{array}$ & $\begin{array}{c}\text { Área de } \\
\text { Contribuição } \\
\text { para o } \\
\text { escoamento } \\
\text { superficial }\left(m^{2}\right)\end{array}$ & $\begin{array}{l}\text { Escoamento } \\
\text { Superficial }\end{array}$ & $\begin{array}{c}\text { Área de } \\
\text { Contribuição } \\
\text { para o } \\
\text { escoamento } \\
\text { superficial }\left(m^{2}\right)\end{array}$ & $\begin{array}{l}\text { Escoamento } \\
\text { Superficial }\end{array}$ \\
\hline $\begin{array}{l}\text { ÁREA } 5 \\
\text { MICROBACIAS }\end{array}$ & 76.460 & $100 \%$ & 59.944 & $78 \%$ & 33.402 & $44 \%$ & 68.234 & $89 \%$ \\
\hline $\begin{array}{l}\text { ÁREA EDIFICAÇÕES } \\
\text { CONSTRUÍDAS }\end{array}$ & 39.601 & $52 \%$ & 33.218 & $43 \%$ & 33.218 & $43,4 \%$ & 33.218 & $43 \%$ \\
\hline ÁREA ECPP & 36.859 & $48 \%$ & 26.725 & $35 \%$ & 185 & $0,2 \%$ & 35.017 & $46 \%$ \\
\hline
\end{tabular}

Fonte: Autores (2015).

\section{Resultados encontrados no ECPP 3: bairro - São José do Rio Preto/SP}

Após a caracterização do ECPP Bairro, foi demarcada a área (sub-bacia) na Figura 8 com maior número de calçadas verdes existentes no bairro e realizada a tipologia de pavimentação. A partir disto, foi elaborada a Tabela 9, onde é apresentada a síntese dos cenários do ECPP Bairro. No cenário real, os ECPPs correspondem a cerca de $9 \%$ da contribuição para o escoamento superficial, situação muito próxima ao cenário desfavorável, onde os ECPPs são considerados $100 \%$ impermeabilizados por concreto convencional e contribuem em $11 \%$ para o escoamento. No cenário favorável, com o escoamento da água de chuva direcionado para as faixas gramadas, considerando que todas as edificações atendem a este critério, os ECPPs contribuem apenas em 2\% para o escoamento superficial.

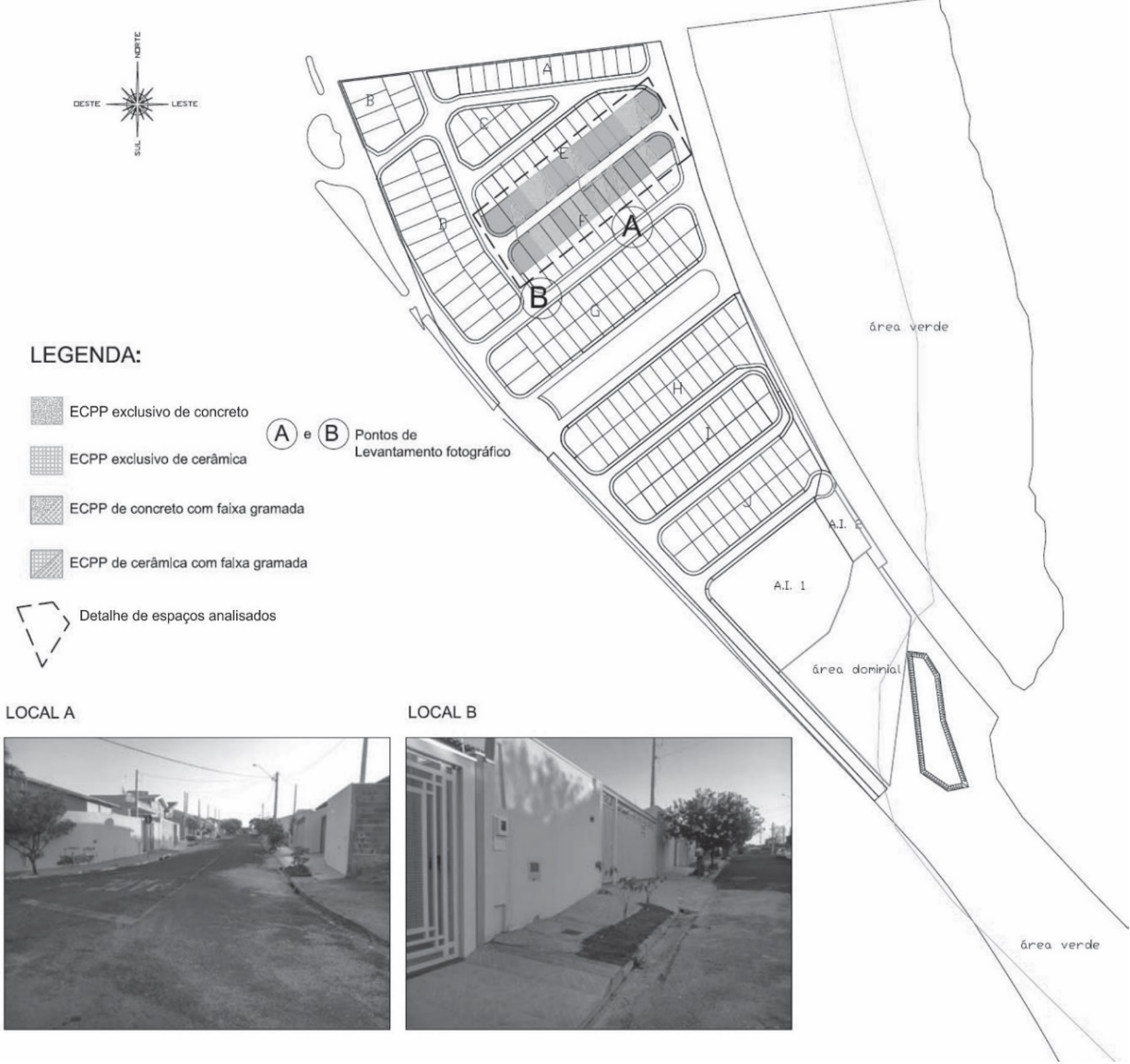

Figura 8 - Delimitação da área de estudo e tipologias de pavimentos. Fonte: Autores (2015). 
Tabela 9 - Síntese dos cenários do ECPP Bairro

\begin{tabular}{|c|c|c|c|c|c|c|c|c|}
\hline \multirow[b]{2}{*}{$\begin{array}{c}\text { CARACTERÍSTICAS DO ECPP } \\
\text { BAIRRO }\end{array}$} & \multirow[b]{2}{*}{$\mathrm{m}^{2}$} & \multirow[b]{2}{*}{$\%$} & \multicolumn{2}{|c|}{ Cenário Real } & \multicolumn{2}{|c|}{ Cenário Favorável } & \multicolumn{2}{|c|}{ Cenário Desfavorável } \\
\hline & & & $\begin{array}{c}\text { Área de } \\
\text { Contribuição } \\
\text { para o } \\
\text { escoamento } \\
\text { superficial } \\
\left(\mathrm{m}^{2}\right)\end{array}$ & $\begin{array}{l}\text { Escoamento } \\
\text { Superficial }\end{array}$ & $\begin{array}{l}\text { Área de } \\
\text { Contribuição } \\
\text { para o } \\
\text { escoamento } \\
\text { superficial } \\
\left(\mathrm{m}^{2}\right)\end{array}$ & $\begin{array}{l}\text { Escoamento } \\
\text { Superficial }\end{array}$ & $\begin{array}{l}\text { Área de } \\
\text { Contribuição } \\
\text { para o } \\
\text { escoamento } \\
\text { superficial } \\
\left(m^{2}\right)\end{array}$ & $\begin{array}{l}\text { Escoamento } \\
\text { Superficial }\end{array}$ \\
\hline Área de Estudo & 8.722 & $100 \%$ & 7.348 & $84 \%$ & 4.752 & $54 \%$ & 8.412 & $96 \%$ \\
\hline Área de Lotes ocupados & 3.475 & $40 \%$ & 3.302 & $38 \%$ & 2.516 & $29 \%$ & 5.625 & $64 \%$ \\
\hline Área de Lotes não ocupados & 2.310 & $26 \%$ & 1.386 & $16 \%$ & - & - & - & - \\
\hline Áreas Verdes dentro do Lote & 135 & $2 \%$ & 28 & $0 \%$ & 186 & $2 \%$ & - & - \\
\hline Área Asfaltada & 1.936 & $22 \%$ & 1.839 & $21 \%$ & 1.839 & $21 \%$ & 1.839 & $21 \%$ \\
\hline Área ECPP & 844 & $10 \%$ & 788 & $9 \%$ & 182 & $2 \%$ & 949 & $11 \%$ \\
\hline Faixa Gramada & 22 & $0 \%$ & 5 & $0 \%$ & 28 & $0 \%$ & - & - \\
\hline
\end{tabular}

Fonte: Autores (2015).

\section{Síntese dos resultados encontrados nos três ECPPs}

Nos cenários favoráveis, o ECPP-UFSCar e o ECPP- Bairro alcançaram índices iguais de contribuição dos ECPPs, isto porque a solução dada para ambos prevê o direcionamento das águas da chuva para os gramados em volta dos ECPPs no caso da UFSCar, e, no caso do bairro, para as Faixas Gramadas, como determina a Lei municipal 10.822 .

O cenário favorável do ECPP-Calçadão alcançou níveis próximos a $0 \%$ de escoamento superficial, isso porque foi considerada a troca da pavimentação por pisos drenantes, que possibilitam infiltração quase total da água de chuva, seu índice de infiltração é muito próximo ao do solo gramado, como visto na bibliografia.

Porém, no cenário desfavorável, os ECPPs do Calçadão contribuiriam em 46\% do escoamento superficial, por ser considerado como totalmente impermeabilizado por concreto convencional. O ECPP - Bairro contribuiria em apenas $11 \%$, por ser menor a área destinada aos ECPPs; o mesmo ocorre com o ECPP-UFSCar, que, por estar em uma área rica em espaços gramados, acabou contribuindo no cenário ruim em apenas $11 \%$ de escoamento superficial.

A Figura 9 apresenta um gráfico resultante dos cenários de contribuição para o escoamento superficial que simplifica essa análise, o que evidencia como o escoamento no Cenário Favorável seria muito menor em todos os três ECPPs.

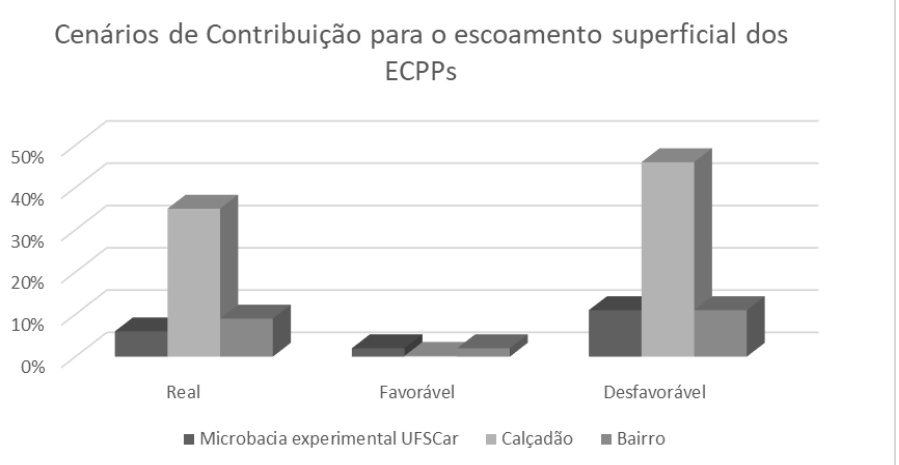

Figura 9 - Resumo dos Cenários de Contribuição para o escoamento superficial dos ECPPs. Fonte: Autores (2016).

Constatou-se que, no ECPP UFSCar, embora haja uma grande área gramada ao redor destes espaços, ela não é utilizada como área para infiltração, pois vários trechos contêm guias laterais que impedem o acesso do escoamento superficial (ou o gramado situa-se numa cota superior). Isto faz com que tais trechos se tornem canais de água de chuva que vão direto para a rede de drenagem. A solução neste caso seria apenas direcionar 
adequadamente o escoamento das águas de chuva para estes locais de infiltração, sem a necessidade de implantar pisos drenantes.

No caso do ECPP-Calçadão, a necessidade de áreas pavimentadas é maior, em função do número de usuários, dificultando a implantação de áreas mais permeáveis, como gramados. Deste modo, passa a ser mais importante o uso de pisos drenantes, que possuem taxas de permeabilidade altas, desde que associados a sistemas de reservação ou infiltração nos espaços abaixo deles. Porém, um desenho urbano de mais qualidade também seria adequado, com o maior emprego de faixas gramadas, maior arborização e espaços ajardinados, como também a implantação de jardins de chuva.

Para alcançar o cenário favorável no ECPP Bairro, como já existe legislação específica que exige a execução das faixas gramadas, chamadas "Calçadas Verdes", seria necessária uma maior fiscalização do poder público. A fiscalização deveria acontecer tanto na implantação dos ECPPs quanto posteriormente, pois em muitos casos as faixas gramadas foram concretadas após a obtenção do "Habite-se". Além disto, também é necessário garantir que o escoamento seja direcionado para os locais gramados, sem a colocação de guias que sirvam de obstáculo.

\section{Conclusão}

O presente trabalho permitiu chegar a algumas conclusões, apresentadas em função dos aspectos abordados. Observou-se que a impermeabilização causada pelos ECPPs pode ser equivalente à área das edificações existentes, o que foi bem caracterizado no ECPP-UFSCar, e não ocorreu nos outros dois ECPPs estudados, nos quais as áreas das edificações ou vias para veículos foram maiores. Mesmo assim, a sua contribuição para o escoamento superficial é significativa. Neste sentido, as comparações feitas a partir de diferentes cenários permitiram identificar as reduções de escoamento que poderiam ser obtidas projetando-se os ECPPs de modo hidrologicamente funcional.

Outra alternativa seria que a responsabilidade pela manutenção e execução das calçadas fosse do poder público e não dos moradores, dessa forma, seria possível manter as faixas gramadas em boas condições de infiltração.

De modo geral, conclui-se que, para que um ECPP seja considerado hidrologicamente funcional, não é necessário que seja permeável. Soluções projetuais que permitam um encaminhamento adequado do escoamento superficial podem ser obtidas com o mesmo grau de impermeabilização.

Portanto, é possível projetar e executar grandes áreas para pedestres, com um desenho urbano de mais qualidade, mesclando áreas pavimentadas com grandes áreas verdes, que auxiliem na infiltração da água de chuva. Assim se reduzem gastos com a drenagem urbana convencional, melhorando a qualidade de caminhada do pedestre, e também permite uma paisagem mais agradável, além do auxílio à manutenção de uma temperatura confortável.

Sendo assim, diretrizes para a utilização de pisos hidrologicamente funcionais seriam mais adequadas para o planejamento das cidades como meio de reduzir os impactos causados pela drenagem convencional. Estes pisos podem ajudar a reduzir a ocorrência de enchentes e, quando realizadas as manutenções, se apresentam como bom caminho para pedestres. As prefeituras poderiam investir em propostas para áreas de expansão das cidades, reduzindo gastos com drenagem convencional e não sobrecarregando os sistemas já existentes.

Para que isso aconteça, seria necessária uma visão integrada entre Plano Diretor, Plano de Drenagem Urbana e Código de Obras, em que o manejo de águas pluviais pudesse ser implantado como norma construtiva e forma de mitigação dos efeitos do crescimento urbano. Por meio de legislações de uso e ocupação do solo mais restritivas e de cuidado e ampliação das áreas verdes, bem como a proteção de mananciais e áreas de recarga de aquífero dos municípios. 


\section{Referências}

Araújo, P. R., Tucci, C. E. M., \& Goldenfum, J. A. (2000). Avaliação da eficiência dos pavimentos permeáveis na redução de escoamento superficial. Revista Brasileira de Recursos Hídricos, 5(3), 46-54.

http://dx.doi.org/10.21168/rbrh.v5n3.p21-29.

Associação Brasileira de Normas Técnicas - ABNT. (2015). ABNT NBR 9050: acessibilidade a edificações, mobiliário, espaços e equipamentos urbanos. Rio de Janeiro: ABNT.

Baptista, M., Nascimento, N., \& Barraud, S. (2005). Técnicas Compensatórias em Drenagem Urbana. Porto Alegre: ABRH.

Brasil. (1979, 19 de dezembro). Lei Federal no 6766 de 19 de dezembro de 1979. Dispõe sobre o Parcelamento do Solo Urbano e dá outras Providências. Brasília: Diário Oficial da União.

Bruno, L. O., Amorim, R. S. S., \& Silveira, A. (2013). Estudo da redução do escoamento superficial direto em superfícies permeáveis. Revista Brasileira de Recursos Hídricos, 18(2), 237-247.

http://dx.doi.org/10.21168/rbrh.v18n2.p237-247.

Ferguson, B. K. (2012). A unified model for integral city design. Management of Environmental Quality, 23(2), 140149. http://dx.doi.org/10.1108/14777831211204895.

Instituto Brasileiro de Geografia e Estatística - IBGE. (2010). Censo 2010. Rio de Janeiro.

Parra, G. G., Masiero, E., Barbato, R. C., \& Belentani, V. M. R. (2011). Histórico das inundações em São José do Rio Preto. In Anais do Encontro Latino-Americano sobre Edificações e Comunidades Sustentáveis (ELECS) (1 CD-ROM). São Leopoldo: Unisinos.

Parra, G. G., \& Teixeira, B. A. N. (2015). Análise da permeabilidade e dos métodos de Instalação de pavimentos permeáveis contidos em artigos científicos e em catálogos técnicos. Revista Nacional de Gerenciamento de Cidades, 3(15), 142-157. http://dx.doi.org/10.17271/2318847231520151013.

Prefeitura Municipal de São José do Rio Preto (2015). Projeto técnico Bairro Jardim Indianápolis. São José do Rio Preto: Secretaria Municipal de Obras.

Rio Preto Classificados (2015). Localização. Recuperado em 9 de dezembro de 2015, de http://riopretoclassificados.com.br/localizacao_sao_jose_rio_preto.php.

São José do Rio Preto. (2010, 17 de novembro). Lei municipal no 10.822, de 17 de novembro de 2010. Institui o Programa de Recuperação e Preservação da Permeabilidade do solo. São José do Rio Preto: Diário Oficial.

São Paulo. (2011, 10 de setembro). Lei municipal no 15.442, de 9 de setembro de 2011. Dispõe sobre a limpeza de imóveis, o fechamento de terrenos não edificados e a construção e manutenção de passeios, bem como cria o DisqueCalçadas. São Paulo: Diário Oficial da Cidade.

São Paulo. Prefeitura Municipal. Secretaria de Coordenação das Subprefeituras. (2012). Conheça as regras para arrumar a sua calçada (21 p.). São Paulo.

Wang, D., Wang, L., Cheng, K., \& Lin, J. (2010). Benefit analysis of permeable pavement on sidewalks. International Journal of Pavement Research and Technology, 3(4), 207-215.

Editor: Harry Bollmann

Recebido: Set. 17, 2019

Aprovado: Jun. 17, 2020 